
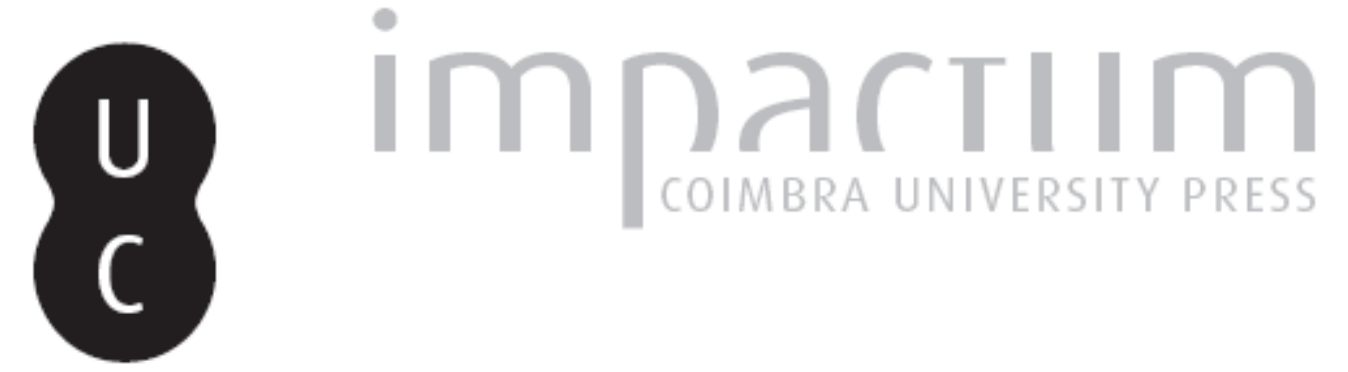

\title{
[Recensão a] M. TRÖSTER, Themes, Character, and Politics in Plutarch's Life of Lucullus. The Construction of a Roman Aristocrat
}

Autor(es): $\quad$ Courrier, Cyril

Publicado por: International Plutarch Society

URL persistente:

URI:http://hdl.handle.net/10316.2/36399

DOI:

DOI:http://dx.doi.org/10.14195/0258-655X_6_9

Accessed : $\quad$ 26-Apr-2023 16:20:17

A navegação consulta e descarregamento dos títulos inseridos nas Bibliotecas Digitais UC Digitalis, UC Pombalina e UC Impactum, pressupõem a aceitação plena e sem reservas dos Termos e Condições de Uso destas Bibliotecas Digitais, disponíveis em https://digitalis.uc.pt/pt-pt/termos.

Conforme exposto nos referidos Termos e Condições de Uso, o descarregamento de títulos de acesso restrito requer uma licença válida de autorização devendo o utilizador aceder ao(s) documento(s) a partir de um endereço de IP da instituição detentora da supramencionada licença.

Ao utilizador é apenas permitido o descarregamento para uso pessoal, pelo que o emprego do(s) título(s) descarregado(s) para outro fim, designadamente comercial, carece de autorização do respetivo autor ou editor da obra.

Na medida em que todas as obras da UC Digitalis se encontram protegidas pelo Código do Direito de Autor e Direitos Conexos e demais legislação aplicável, toda a cópia, parcial ou total, deste documento, nos casos em que é legalmente admitida, deverá conter ou fazer-se acompanhar por este aviso.

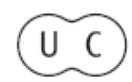




\section{PLOUTARCHOS, n.s.}

Scholarly Journal o

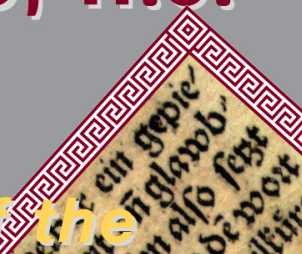

INTERNATIONAL PLUT A N NOS

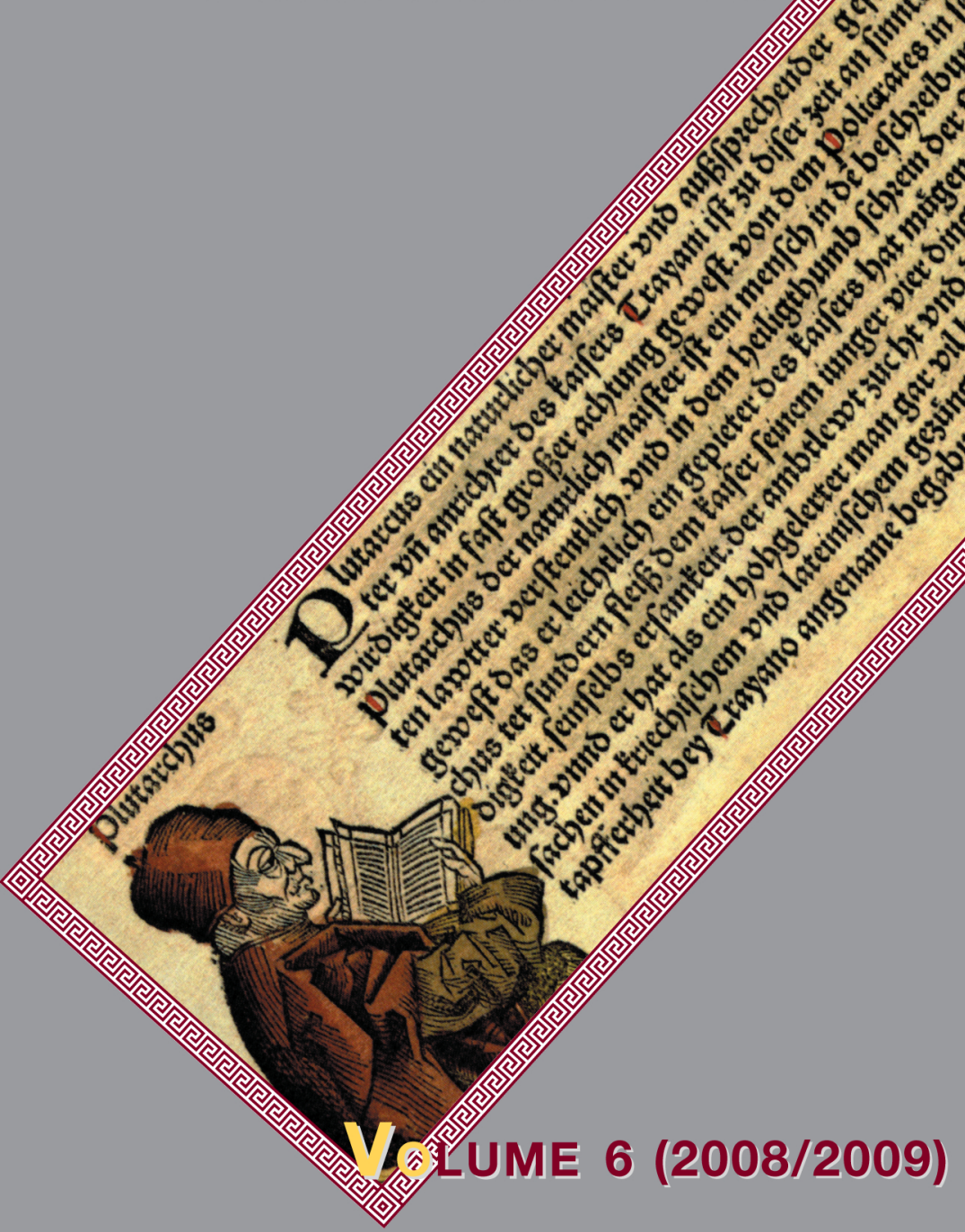

UNIVERSITY of Málaga (SPAin)

Utah State UniVersity, Logan, Utah (U.S.A.) 
públicos, no se deben a la generosidad aristocrática: "responden a las exigencias de autorrepresentación del cuerpo ciudadano, erigido en benefactor colectivo de la polis y agente de su política cultural y artística”, pág. 262. Con el programa de Pericles asistimos a la construcción de monumentos por los que Plutarco siente una viva admiración: "Cada uno de ellos, apenas concluido, era tan bello que tenía ya el carácter de lo antiguo, y tan perfecto que ha conservado hasta hoy el frescor de una obra reciente (...) Parece que estas obras tuvieran un aliento siempre vivo y un espíritu inaccesible a la vejez"3. El capítulo 13 de la Vida de Pericles procura un catálogo completo de sus proyectos, con el Partenón a la cabeza, detallando sus características y dando cuenta también de los arquitectos encargados de las obras. Para terminar, Fidias es el objeto de una "microbiografía" dentro de la biografía plutarquea de Pericles y de un epígrafe, el penúltimo, del libro que estamos reseñando. El artista aparece como el brazo ejecutor del programa del alcmeónida $\mathrm{y}$, consecuentemente, víctima también de los detractores de la política de éste. Plutarco da gran espacio en su texto a las denuncias $\mathrm{y}$ acusaciones contra Fidias aunque, desde el punto de vista estrictamente artístico, lo más interesante son las noticias sobre sus colosales estatuas y esa curiosa referencia, mencionada más arriba, a un posible autorretrato suyo, junto a la efigie de Pericles, en el escudo de la Atenea Pártenos. Este "criptorretrato" de Pericles, junto a otras imágenes del estadista, es comentado en el epígrafe final de este último capítulo.
Elegantemente escrito y bellamente ilustrado con fotografías realizadas, en su mayor parte, por el propio F. Marín, Plutarco y el arte de la Atenas hegemónica constituye una valiosísima aportación, una obra de referencia en el ámbito de los estudios sobre Plutarco. La extensa bibliografía sobre el queronense, conocida y manejada con solvencia por el autor, se ve enriquecida ahora en uno de los aspectos que, comparativamente, había estado más desatendido, el de las artes visuales.

\section{Marta GonzÁlez GonzÁlez Universidad de Málaga}

M. Tröster, Themes, Character, and Politics in Plutarch's Life of Lucullus. The Construction of a Roman Aristocrat, Stuttgart, Franz Steiner Verlag, Historia Einzelschriften - 201, 2008, 206 pages. ISBN : 978-3-515-09124-4.

Parmi les grands personnages du dernier siècle de la République romaine, il en est un qui fut la victime d'un désintérêt de la part des historiens: Lucullus. On ne compte en effet, depuis l'ouvrage que lui consacra M. Villoresi en $1939^{1}$, que trois biographies dédiées au consul de 74 a.C. ${ }^{2}$ C'est avec l'intention clairement affichée de combler en partie ce vide historiographique que $\mathrm{M}$. Tröster propose ici un livre issu de sa thèse de doctorat, relativement court (texte de 160 pages) mais riche d'une importante bibliographie (pp. 162-189) et de deux indices (général et locorum). L'objectif annoncé dès l'introduction est aussi simple dans sa formulation qu'ambitieux dans sa mise en
3

1 M. Villoresi, Lucullo, Florence, 1939.

2 Outre M. Gelzer, “L. Licinius Lucullus [104]”, dans RE, 13, 1, 1926, col. 376-414, il s'agit de J. Van Ooteghem, Lucius Licinius Lucullus, Bruxelles, 1959 ; A. Keaveney, Lucullus. A life, Londres, 1992 et G. Schütz, L. Licinius Lucullus. Studien zu den frühen Jahren eines Nobilis (117-75 v. Chr.), Diss. Regensburg, 1994. 
œuvre : réévaluer l'image traditionnelle de ce personnelle pour la civilisation grecque - ce personnage.Lucullusdemeuredanslamémoire qui ne l'empêchait pas d'être parfaitement collective romaine comme l'introducteur du familiarisé avec elle - mais au contraire le luxe à Rome; son attitude est caractérisée reflet d'une attitude politique consciente et par une excessive fierté d'aristocrate qui en parfaitement maîtrisée, destinée à lui assurer faisait le "général du Sénat»(R. Syme ${ }^{3}$ ), le soutien d'un maximum de cités grecques représentant par excellence des optimates (G. pour son expédition orientale. Lucullus était Schütz), incapable d'obtenir un quelconque un homme politique ambitieux qui poursuivait soutien du peuple comme de ses soldats, sur ses propres buts, comme plus tard Pompée. lesquels il n'avait aucune autorité. À partir Dans le chapitre 6, nous apprenons ainsi que d'une relecture précise du récit de Plutarque, les méthodes diplomatiques de ce dernier l'auteur ambitionne au contraire de montrer furent en grande partie inspirées par celles du que cette vision a été pour une large part consul de 74 a.C. L'ouvrage vise donc à mieux construite par l'historiographie moderne. cerner ce que fut la carrière de Lucullus, dont La lecture des sources avait été biaisée par la compréhension a été déformée par le récit une tradition hostile au général romain et de Plutarque et son insistance sur l'adhésion Lucullus n'était pas celui que ses principaux soi-disant permanente du consul de 74 a.C. biographes modernes ont voulu voir. $M$. à la politique sénatoriale, son opposition à Tröster reproche notamment à ces travaux Pompée et à différents démagogues.

leur perspective purement chronologique se contentant généralement d'une simple retranscription des sources, parfois dénuée de véritable analyse scientifique.

Afin d'éviter cet écueil, l'auteur se propose d'adopter une structure surprenante pour un ouvrage qui s'apparente malgré tout à une biographie, à savoir un plan thématique que l'on peut scinder en deux grandes parties, le premier et le dernier chapitre constituant en réalité l'introduction et la conclusion. Les chapitres 2 et 3 sont plutôt consacrés à l'hellénisme et à la personnalité de Lucullus, les chapitres 4 à 6 étant davantage tournés vers les activités politiques et militaires. Cependant, l'idee qui dirige l'ouvrage est resule en realite de la repre par Cependant, lidé qui dirige l'ouvrage est résulte en réalite de la reprise par l'auteur claire: reconstruire la vie de Lucullus en grec d'une tradition politique hostile au déconstruisant les déformations inhérentes consul, construite dès le $\mathrm{I}^{\text {er }}$ s. a.C. par la au genre biographique du récit plutarquien. propagande pompéienne lorsque celui-ci Par exemple, M. Tröster défend, dans le voulut reprendre la guerre contre Mithridate chapitre 2, l'idée que le philhellénisme de puis, plus tard, au moment de la formation du Lucullus n'était pas, comme l'explique premier triumvirat, dont Lucullus était l'un Plutarque et comme l'historiographie l'a des plus farouches opposants. Pompée, qui repris à sa suite, le résultat d'une fascination bénéficie d'une large place dans cet ouvrage,

3

R. Syme, The Roman Revolution, Oxford, 1939, p. 29. 
aurait en effet instrumentalisé la longue très généraux, à l'utilité parfois douteuse, présence de Lucullus en Orient pour en faire comme les pages 93-98 qui résument à grands l'image romaine du despote oriental, plongé traits le renouvellement historiographique qui dans un luxe outrancier, et qui se serait retiré fit suite aux travaux de F. Millar et de l'école de la vie politique en 66 (ou 63) puis en 59 d'Oxford. Enfin, même si le but avoué de a.C. pour mieux en profiter. Sur la base d'une l'ouvrage était une reconstruction de l'image relecture précise de Plutarque et d'une mise en de Lucullus, et que, pour ce faire, l'auteur perspective de la Vie de Lucullus avec d'autres recourt - à juste titre - à d'autres sources sources, notamment archéologiques, l'auteur littéraires, ainsi qu'à des données épigraphiques soutient au contraire que ces retraits (surtout voire archéologiques, le titre annonçait une le premier) pourraient n'avoir aucune réalité historique, pas plus que son luxe légendaire.

Résulte de cette étude l'image d'un Lucullus, qu'avait déjà entr'aperçue E. Badian mais que M. Tröster parvient à systématiser, à savoir celle d'un politicien ambitieux et d'un général compétent qui poursuivait ses propres objectifs de pouvoir et de prestige, qui n'était pas le général du Sénat ou le type même de l'aristocrate conservateur mais, bien au contraire, un aristocrate typique de la fin de la République, au sens d'une figure classique de la fin du I $^{\text {er }}$ siècle a.C., un politicien versatile dont les interactions avec ses pairs comme avec la multitude étaient soumis à des impératifs personnels d'accumulation de pouvoir, de prestige et de richesse.

Cependant, même convaincant, l'ouvrage n'évite pas quelques écueils, dont le plus important tient sans doute à la structure même de l'ouvrage. En effet, bien qu'il se veuille œuvre d'historien, il oscille entre le commentaire de texte classique, le manuel d'histoire sur la fin de la République romaine et la biographie de Lucullus, sans qu'on perçoive toujours la nature exacte d'un projet qui donne parfois l'impression de manquer d'unité. En outre, le plan thématique contraint l'auteur à de fréquentes redites ou à la rédaction de longs paragraphes introductifs attention particulière portée à la Vie de Lucullus. Si l'œuvre de Plutarque constitue bien la base de l'ouvrage, on regrettera que ce dernier n'ait pas davantage mis l'accent sur la méthode historique de l'auteur grec, certes présentée dans l'introduction, mais à propos de laquelle M. Tröster se contente souvent de noter les emphases propres à l'auteur grec (comme son goût pour les relations entre les dirigeants et la foule) sans vraiment chercher à en comprendre les motivations profondes. Ainsi, s'il est en effet tout à fait convaincant que la seule image de Lucullus à nous être parvenue résulte d'une construction élaborée par la propagande pompéienne, il semble plus difficile de croire, compte tenu des recherches les plus récentes sur Plutarque ${ }^{4}$, que ce dernier n'ait pas perçu le caractère pleinement biaisé de ses sources, qu'il se serait contenté de reprendre sans vraiment les analyser (p. 152). Toujours est-il que ces quelques problèmes ne doivent en rien constituer un frein à la lecture d'un ouvrage qui apporte un éclairage intéressant et novateur sur la vie d'un grand aristocrate et plus largement sur les turbulences politiques que connut la fin de la République.

\section{Cyril Courrier Université de Lyon, ENS-LSH}

4

Voir en dernier lieu P. Schmitt-Pantel, "Anecdotes et histoire chez Plutarque. État de la question et interrogations", Europe, "Historiens de l'Antiquité", janvier-février 2008, pp. 236-251. 